\title{
New, but still the same old story
}

From the Department for Cardiothoracic Surgery, University Hospital Bergmannsheil, Ruhr University Bochum, Bochum, Germany.

Disclosures: J.F.B. has received travel expenses and lecture fees from Thoratec, now part of Abbott, manufacturer of the HeartMate II and HeartMate III.

Received for publication April 20, 2018; accepted for publication April 20, 2018; available ahead of print May 18, 2018.

Address for reprints: J. F. Matthias Bechtel, MD, Klinik fuer Herz- und Thoraxchirurgie, Berufsgenossenschaftliches Universitaetsklinikum Bergmannsheil, Ruhr- Universitaet Bochum, Buerkle-de-la-Camp-Platz 1, Bochum 44789, Germany (E-mail: matthias.bechtel@bergmannsheil.de).

J Thorac Cardiovasc Surg 2018;156:1528-9

0022-5223/\$36.00

Copyright (c) 2018 by The American Association for Thoracic Surgery

https://doi.org/10.1016/j.jtcvs.2018.04.089

In this issue of the Journal, Hawkins and colleagues ${ }^{1}$ report that postoperative atrial fibrillation (POAF) after implantation of rotatory left ventricular assist devices (LVADs) in patients without previous atrial fibrillation is associated with an increase of postoperative complications, longer hospital stays, higher costs, and a higher frequency of discharge into a facility. Their findings mirror what is known about POAF from other types of cardiac surgery, and it seems plausible that this holds true for the most ill patients who are typically seen in LVAD surgery. This has not been demonstrated so clearly before, however, and Hawkins and colleagues ${ }^{1}$ are to be congratulated for undertaking this study.

Nevertheless, it should be noted that the article of Hawkins and colleagues ${ }^{1}$ is based on a retrospective multicenter study, and that no causal relationship can therefore be determined. In clear words, we do not know that the occurrence of atrial fibrillation causes the complications; it is also possible that atrial fibrillation is only a sign or marker for other more relevant complications, such as right ventricular failure, as supposed by Hawkins and colleagues. ${ }^{1}$ This interpretation is supported by the finding that POAF was not associated with an increase of postoperative stroke.

The implementation of rotatory LVADs is a success story. Their use has made the treatment of terminal heart failure with LVAD-implantation much safer, ${ }^{2}$ and for many patients, these machines prolong life with a considerable quality of life. As a result, LVAD implantation is now explicitly recommended under certain circumstances in the treatment of terminal heart failure ${ }^{3,4}$ and will most likely be used more often in the next years. LVAD therapy still has some drawbacks that can have dramatic impact on our patients' lives, however, and it is very expensive. Both aspects place us under obligation to identify patients who are most likely to benefit.

Unfortunately, the study by Hawkins and colleagues ${ }^{1}$ provides few hints regarding how to tailor LVAD therapy-but that was beyond the scope of the study. It is not surprising

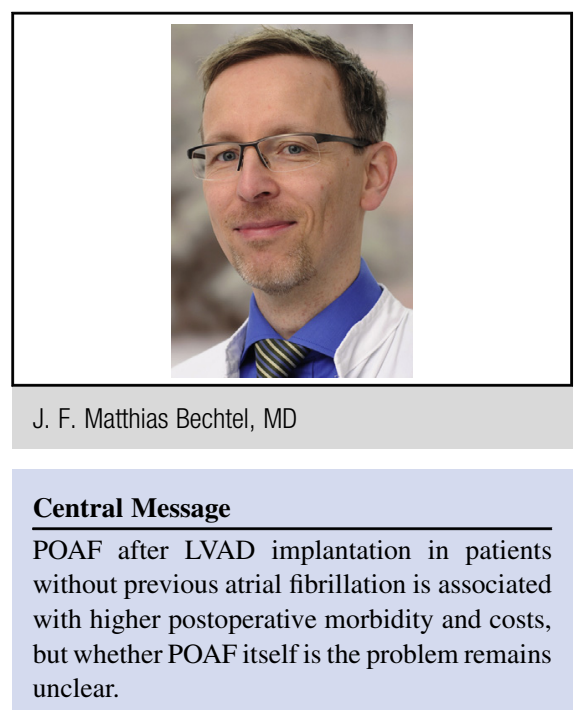

See Article page 1543 .

that patients with POAF were older, more likely to have mitral valve regurgitation, and more likely to undergo tricuspid valve surgery. It is of some interest that POAF was more likely to occur in patients who had a centrifugal, intrapericardial pump than in those with an axial pump, which is usually placed just outside the pericardium. It appears possible that intrapericardial placement may irritate the heart and trigger atrial fibrillation, although a literature search shows that this has not been scrutinized. The literature provides little or no evidence, however, that centrifugal intrapericardial pumps are associated with higher rates of right ventricular failure and with worse outcomes. ${ }^{5-8}$

It will be the task for future studies to examine factors associated with outcome of LVAD therapy. It seems prudent that such studies evaluate not only mortality itself but functional survival. ${ }^{9}$ Meanwhile, it is still the same old story that careful preoperative evaluation of all patients with special emphasis on right heart function and implementation of all intraoperative and postoperative measures to protect the right ventricle are of uppermost importance in LVAD surgery.

\section{References}

1. Hawkins RB, Mehaffey JH, Guo A, Charles EJ, Speir AM, Rich JB, et al Postoperative atrial fibrillation is associated with increased morbidity and resource utilization after left ventricular assist device placement. J Thorac Cardiovasc Surg. 2018;156:1543-9.e4.

2. Slaughter MS, Rogers JG, Milano CA, Russell SD, Conte JV, Feldman D, et al; HeartMate II Investigators. Advanced heart failure treated with continuous-flow left ventricular assist device. N Engl J Med. 2009;361:2241-51. 
3. Yancy CW, Jessup M, Bozkurt B, Butler J, Casey DE Jr, Colvin MM, et al. 2017 ACC/AHA/HFSA focused update of the 2013 ACCF/AHA guideline for the management of heart failure: a report of the American College of Cardiology/American Heart Association task force on clinical practice guidelines and the Heart Failure Society of America. Circulation. 2017;136:e137-61.

4. Ponikowski P, Voors AA, Anker SD, Bueno H, Cleland JG, Coats AJ, et al. 2016 ESC guidelines for the diagnosis and treatment of acute and chronic heart failure: the task force for the diagnosis and treatment of acute and chronic heart failure of the European Society of Cardiology (ESC) developed with the special contribution of the Heart Failure Association (HFA) of the ESC. Eur Heart J. 2016;37:2129-200. Erratum in: Eur Heart J. 2016;39: 1206.

5. Topkara VK, O’Neill JK, Carlisle A, Novak E, Silvestry SC, Ewald GA. HeartWare and HeartMate II left ventricular assist devices as bridge to transplantation: a comparative analysis. Ann Thorac Surg. 2014;97: 506-12.

6. Tsiouris A, Paone G, Nemeh HW, Borgi J, Williams CT, Lanfear DE, et al. Shor and long term outcomes of 200 patients supported by continuous-flow left ventricular assist devices. Word J Cardiol. 2015;7:792-800.

7. Haglund NA, Davis ME, Tricarico NM, Keebler ME, Maltais S. Readmissions after continuous flow left ventricular assist device implantation: differences observed between two contemporary device types. ASAIO J. 2015;61: 410-6.

8. Mehra MR, Naka Y, Uriel N, Goldstein DJ, Cleveland JC Jr, Colombo PC, et al. A fully magnetically levitated circulatory pump for advanced heart failure. $N$ Engl J Med. 2017;376:440-50.

9. Bechtel JF, Strauch JT. Examining the future in retrospect. J Thorac Cardiovasc Surg. 2017;154:1554-5. 